\title{
Regulation of Fetal Lamb Ductus Arteriosus Smooth Muscle Cell Migration by Indomethacin and Dexamethasone
}

\author{
ROBERT KOPPEL AND MARLENE RABINOVITCH
}

\begin{abstract}
Divisions of Neonatology and Cardiovascular Research. Research Institute. The Hospital for Sick Children. Toronto, Ontario, M5G IX8 Canada; and Departments of Pediatrics and Pathology, University of Toronto. Toronto, Canada
\end{abstract}

\begin{abstract}
Postnatal closure of the ductus arteriosus (DA) requires the development, during late gestation, of "intimal cushions." These structures, which partially occlude the vessel lumen, are characterized by smooth muscle cell (SMC) migration into an expanded subendothelium. DA SMC migration is dependent upon increased fibronectin $(\mathrm{FN})$ production. We hypothesized that indomethacin (INDO) or dexamethasone, which could influence FN production, may affect SMC migration and DA intimal cushion formation. SMC harvested from the DA and aorta of 100 d fetal lambs were seeded onto three-dimensional collagen gels. Migration into the gels was quantitatively assessed by phase-contrast microscopy. INDO retarded DA SMC migration $(p<0.05)$, but it had no effect on aorta SMC migration. Synthesis of FN was measured after ${ }^{35} \mathrm{~S} \mid$-methionine radiolabeling of cells, gelatin sepharose extraction of conditioned media, and resolution by SDS-PAGE. Despite the decrease in migration, INDO did not affect FN synthesis in DA SMC, whereas dexamethasone, a stabilizer of FN mRNA that increased DA FN synthesis by $44 \%$, had no further effect on SMC migration. We then investigated whether INDO might be influencing SMC migration by decreasing collagenase production or altering cell shape through changes in $\mathrm{F}$-actin polymerization. Collagenase activity, assessed by zymography using collagen types I and IV, was similar in control and treated DA and aorta cells. Image analysis of the actin cytoskeleton after rhodamine-phalloidin staining of DA SMC, however, revealed significant shortening of INDO-treated DA SMC relative to control, consistent with the observed reduction in migration. The results suggest that INDO may inhibit DA SMC migration by altering cell shape, whereas DA SMC are not further influenced by dexamethasone-mediated increases in $\mathrm{FN}$. These findings may provide insight into the mechanism of INDO treatment failure in preterm infants if repeated use of INDO has an unforeseen adverse effect on DA closure by retarding intimal cushion formation. (Pediatr Res 33: 352-358, 1993)
\end{abstract}

\section{Abbreviations}

DA, ductus arteriosus

SMC, smooth muscle cell

INDO, indomethacin

Received September 8, 1992; accepted December 10, 1992

Correspondence: Marlene Rabinovitch, M.D., Division of Cardiovascular Research, The Hospital for Sick Children, 555 University Ave., Toronto, Ontario, M5G 1 X8 Canada.

Supported by a grant from the Medical Research Council of Canada, No. MT5426. R.K is a fellow in the Neonatal-Perinatal Medicine Training Program, University of Toronto. M.R. is a Career Investigator of the Heart and Stroke Foundation of Ontario.
DEX, dexamethasone

Ao, aorta

PG, prostaglandin

FN, fibronectin

The DA is an artery that, during fetal life, serves to divert the flow of blood from the uninflated lungs to the systemic circulation. With the initiation of breathing, the lungs are inflated and the arterial oxygen saturation increases. Through a cytochrome P-450 mechanism (1) probably linked to endothelin $(2,3)$, the elevated oxygen tension produces a strong muscular contraction occluding the DA and increasing the flow of blood to the pulmonary circulation. Independent of this reversible muscular contraction, permanent closure of the DA requires a structural change, namely, the development of "intimal cushions" (4). Failure of the DA to undergo obliteration, a common event in preterm newborns, allows blood to flow from the Ao into the pulmonary circulation and results in congestive heart failure.

The development of intimal cushions, which occurs independently of DA muscular contraction, involves changes in both the intima and the media of the vessel with increased deposition of hyaluronan in the subendothelial region associated with migration of SMC into this area (5). Studies by Boudreau and Rabinovitch (6) revealed that DA SMC harvested from early gestation fetal lambs produced 2-fold more FN than SMC from the Ao. Furthermore, the increase in FN production by DA SMC was associated with their enhanced migration relative to Ao SMC in a three-dimensional collagen gel (7).

In a study evaluating the relationship between PG and intimal cushion formation, deReeder et al. (8) observed diminished immunohistochemical staining for prostacyclin synthase in DA sections from a genetic strain of poodle dog with patent DA. The presence of $\mathrm{PGE}_{2}$ could not be demonstrated in either the normal or persistently patent DA (8). This suggests that although $\mathrm{PGE}_{2}$ is a regulator of ductal patency, it is the production of prostacyclin that may be required for intimal cushion formation. Because prostacyclin is an agent that increases intracellular levels of cAMP (9), a stimulator of FN gene transcription (10), it may well be important in regulating the structural development of the DA in addition to its physiologic function of maintaining fetal DA patency.

Two commonly used drugs may exert an influence on DA intimal cushion formation in the preterm infant. DEX, a synthetic glucocorticoid, has been shown to increase the biosynthesis of $\mathrm{FN}$ in a fibrosarcoma cell line by increasing mRNA stability and therefore message half-life (11). On this basis, we speculated that treatment of DA SMC with DEX might enhance the migration of these cells by even further increasing their production of 
FN. Conversely, INDO, a cyclooxygenase inhibitor that prevents production of $\mathrm{PG}$ including both $\mathrm{PGE}_{2}$ and $\mathrm{PGI}_{2}$, may downregulate DA SMC FN production and hence migration by interfering with the prostacyclin-mediated cAMP stimulation of transcription of the FN mRNA.

In addition to $\mathrm{FN}$, there are other factors involved in the process of cell migration. Two such factors, of interest because they are also influenced by INDO, are the production of collagenase and the polymerization of F-actin. For cells to migrate through the extracellular matrix, they must produce proteolytic enzymes for matrix component degradation. This is seen during the invasion of tumor cells into basement membranes, as well as during the normal implantation of embryos into uterine linings (12, 13). Rajabi et al. (14) have demonstrated inhibition by INDO of the estradiol-induced increase in cervical SMC production of collagenase. Collagenase activity was also increased by treatment of the cells with $\mathrm{PGF}_{2} \alpha$ or $\mathrm{PGE}_{2}$ (14). In addition. release of collagenase from neutrophils is inhibited by a variety of nonsteroidal antiinflammmatory drugs including INDO (15). INDO has also been shown to inhibit migration of corneal epithelial cells and to promote a "spreading" form of translocation on the basis of actin filament reorganization (16). F-actin regulates neutrophil chemotaxis by determining neutrophil deformability, a feature that is enhanced by $\mathrm{PGE}_{2}$-mediated increases in CAMP (17).

Therefore, we hypothesized that DEX therapy may enhance SMC migration and hence intimal cushion formation by increasing DA SMC FN synthesis, whereas INDO therapy may retard intimal cushion formation by decreasing $\mathrm{FN}$ or collagenase production or by interfering with the polymerization of F-actin. The objectives of this study were first to determine whether treatment of DA and Ao SMC with INDO or DEX increases or decreases their migratory behavior. We then determined whether the effect of INDO and DEX on SMC migratory behavior was related to an effect on FN production. Next, we evaluated the influence of INDO and DEX on SMC production of collagenases involved in cell migration. We then addressed how INDO and DEX may influence the polymerization of F-actin and thereby cell length and shape.

\section{MATERIALS AND METHODS}

In vitro assessment of SMC migration. Fetal Rambouillet lambs were delivered by cesarean section on d 100 of a 145-d timed gestation. We chose this time point because it precedes the full development of intimal cushions. Lamb DA at this gestational age are capable of only weak constriction without luminal obliteration (18). Furthermore, we had previously shown in SMC harvested from fetal lambs at this gestational age that the increase in DA compared with Ao SMC migration was related to increased $\mathrm{FN}(7)$. On the other hand. FN production is similar in DA and Ao cells harvested from 138-d gestation vessels (6), probably reflecting the cessation of increased FN production and SMC migration as formation of the cushion is complete. The maternal ewes were anesthetized by induction with $30 \mathrm{mg} / \mathrm{kg}$ pentobarbital and by ventilation with methoxyflurane, $1.5 \mathrm{~L} /$ min; nitrous oxide, $8 \mathrm{~L} / \mathrm{min}$; and oxygen, $3 \mathrm{~L} / \mathrm{min}$. The lambs were maintained in $100 \%$ nitrogen to prevent breathing and closure of the DA. The great vessels, including the DA, were removed en bloc as previously described (19). Handling and care of animals were in accordance with the guidelines of the Medical Research Council of Canada, and this study protocol was approved by the Animal Care Committee of the Hospital for Sick Children, Research Institute.

SMC were propagated in $25-\mathrm{mL}$ flasks from explants of the media (20) of the vessel wall, and cells were maintained in Medium M199 with 25 mM HEPES ( $N$-2-hydroxyethylpiperazine- $N^{\prime}$-2-ethane sulfonic acid) buffer and glutamine, $1 \%$ antibiotics/antimycotics (Gibco, Burlington, Ontario, Canada), and $10 \%$ FCS (19). SMC at passage 2 were used to provide adequate numbers of cells, and positive identification of SMC was achieved by staining for smooth muscle actin. Protein synthesis has been shown in previous studies not to be influenced by passage number or time in culture at least up to passage 4 (19).

Collagen gels were prepared using bovine dermal type I collagen (Vitrogen 100, Collagen Corp.. Montreal, Quebec, Canada) by following the protocol of Wren et al. (21). Passage 2 SMC were trypsinized at confluence and cell number was determined in triplicate using a Coulter Counter (Coulter Electronics, Hialeah, FL). In six different experiments, aliquots of $5 \times 10^{4} \mathrm{SMC}$ from DA and Ao were seeded onto the surface of each gel. Attachment efficiencies were determined by Coulter Counter after $\mathrm{l} \mathrm{h}$ and were similar between groups. The cells were maintained as described above or with added INDO $10^{-4} \mathrm{M}$ (Sigma Chemical Co., St. Louis, MO) or DEX $5 \times 10^{-7} \mathrm{M}$ (Sigma). These doses were similar to those previously used in cultured cells to inhibit PG synthesis (22) and up-regulate FN synthesis, respectively (23). Phase contrast microscopy with a $10 \times$ objective (Nikon Diaphot inverted microscope; Nikon, Mississauga, Ontario, Canada) was performed on the 2 nd and 5 th day after seeding. Using an eyepiece micrometer and the fine focus calibrator, the number of cells on or below the gel surface in five randomly selected adjacent fields $(0.92 \times 1.30 \mathrm{~mm})$ defined by the photographic grid on the lens was counted at each time point (7).

In vitro assessment of $F N$ synthesis. We measured $F N$ synthesis in five different experiments. In each experiment, $5 \times 10^{4} \mathrm{SMC}$ from the DA and Ao were transferred to $35-\mathrm{mm}$ Petri dishes, grown to confluence, and incubated in methionine-free Medium $\mathrm{M} 199$ for $24 \mathrm{~h}$ in the presence of $10 \mu \mathrm{Ci} / \mathrm{mL}\left[{ }^{35} \mathrm{~S}\right]$-methionine alone or with added INDO $10^{-4} \mathrm{M}$ or DEX $5 \times 10^{-7} \mathrm{M}$. The culture medium was removed and protease inhibitors, including $2 \mathrm{mM}$ phenylmethylsulfonyl fluoride (PMSF, Kodak, Rochester, NY), $10 \mathrm{mM}$ N-ethylmaleamide, and EDTA (Sigma), were added. FN separation was performed by applying $400-\mu \mathrm{L}$ aliquots of medium to a gelatin 4B-sepharose microcolumn (Pharmacia, Uppsala, Sweden) as previously described (24). The gelatin packing was boiled for $3 \mathrm{~min}$ in $200 \mu \mathrm{L}$ of SDS-sample buffer to elute the FN, which was then resolved under reducing conditions on $5 \%$ SDS-PAGE by the method used by Laemmli (25). Gels were treated with $\mathrm{En}^{3}$ hance (DuPont, Boston, MA), dried on a BioRad model 443 slab dryer (Bio-Rad Laboratories, Richmond, CA), and exposed to Kodak X-Omat AR-5 film at $-70^{\circ} \mathrm{C}$ for 3 d. Autoradiographs were used as templates to cut bands at 220 $\mathrm{kD}$ from the gels for determination of radioactive counts by liquid scintillation spectrometry. The identification of the band at $220 \mathrm{kD}$ as FN was previously confirmed by Western immunoblotting. Standardization for cell number was performed by determining DNA content using the fluorescent dye bisbenzamide (Hoescht Reagent H3313, Calbiochem, La Jolla, CA) binding method as previously described (26). Results are expressed as $\mathrm{cpm} / 100 \mathrm{ng} \mathrm{DNA} \times 10^{4}$.

In vitro assessment of collagenase activity. Conditioned media were obtained from duplicate cultures of $5 \times 10^{4} \mathrm{DA}$ and Ao SMC incubated for $24 \mathrm{~h}$ in serum-free medium with the same concentrations of INDO or DEX as described above. Substrate gel electrophoresis using $10 \%$ polyacrylamide containing $1 \mathrm{mg} /$ $\mathrm{mL}$ of type I collagen or gelatin was then performed using the conditioned medium combined with sample buffer lacking $\beta$ mercaptoethanol (27). The gels were then incubated in $2 \%$ Triton $\mathrm{X}-100$ for $30 \mathrm{~min}$ at room temperature and in substrate buffer ( $50 \mathrm{mM}$ Tris- $\mathrm{HCl}$ buffer, $\mathrm{pH} 8$, containing $5 \mathrm{mM} \mathrm{CaCl}_{2}$ ) overnight at $37^{\circ} \mathrm{C}$, after which they were stained with Coomassie blue R-250. Collagen or gelatin degrading enzymes appeared as clear bands on a dark blue background. Molecular weight standards were used to confirm the identity of the enzyme.

Assessment of cell morphology and length. SMC harvested from the DA and Ao of three different fetal lambs were incubated for $24 \mathrm{~h}$ in M199 containing INDO at $10^{-4} \mathrm{M}$ or DEX at $5 \times$ $10^{-7} \mathrm{M}$ in four-well chamber slides (NUNC, Napierville, IL). 
Cells were fixed with $3 \%$ paraformaldehyde, permeabilized with $0.1 \%$ Triton, and stained with rhodamine-phalloidin (1:10) (Molecular Probes, Eugene, OR) for $30 \mathrm{~min}$. Coverslips were mounted with glycerol/PBS (1:1). In each experiment, cells were examined by epifluorescence microscopy at $40 \times$ magnification and cell length was quantified by measuring 30 randomly selected cells on four different slides per cell type and treatment condition using semiautomatic interactive image analysis on an IBAS computer (Kontron, Munich, Germany).

Analysis of data. Migration values at each time point, as well as cell lengths, were compared by analysis of variance followed by Tukey's test to determine which specific groups were different. FN determinations in Ao and DA, with or without INDO and with or without DEX, were compared by $t$ test. Comparisons with $p$ values less than 0.05 were considered significantly different.

\section{RESULTS}

Cell migration studies. In the six experiments, no significant differences were observed in DA and Ao SMC migration through the collagen gels on 2 after seeding (Fig. 1). This reflects similar attachment efficiencies (data not shown). On d 5, we confirmed the previously described increased migratory behavior of DA relative to Ao SMC $(p<0.05)(7)$. Furthermore, we noted a reduction at $\mathrm{d} 5$ in migration of DA SMC in the presence of INDO $(p<0.05)$ to the level apparent in the Ao where INDO had no effect. Although values were slightly higher, the effect of DEX on DA SMC migration was not significant and DEX also did not influence Ao SMC migration.

$F N$ determination. We confirmed in five additional experiments the previously described, approximately 2 -fold increase in FN production by DA relative to Ao SMC $(p<0.05)(6)$ (Fig. 2). Although INDO treatment had no effect on DA SMC FN production, DA SMC treated with DEX secreted $44 \%$ more FN relative to control DA SMC $(p<0.05)$ (Fig. 2). Thus, the INDOinduced decreased DA SMC migration was not related to a reduced production of FN, nor was the DEX-induced additional increase in FN reflected in enhanced migration. Neither INDO nor DEX had a significant effect on FN production by Ao SMC (Fig. 2).

Collagenase studies. Substrate gel electrophoresis in two different experiments revealed similar type I collagenase activity produced by both DA and Ao SMC under control conditions, as well as during treatment with INDO or DEX (Fig. 3). Similar findings were obtained on substrate gel electrophoresis using gelatin, i.e. there was no significant difference in type IV collagenase activity related to treatment or cell type.

Cell morphology and length. On three-dimensional collagen gels, DA cells were elongated and spindle-shaped, whereas the Ao cells appeared shorter and stellate, features we have previously described (7). When DA cells were treated with INDO, they became more like the Ao cells in appearance (Fig. 4). This difference was more evident after rhodamine-phalloidin staining of F-actin (Fig. 5). Quantitative analysis confirmed the shortening of the cells $(p<0.01)$ (Fig. 6). No difference was observed with DEX in DA SMC morphology. INDO had no significant effect on Ao SMC, but DEX was associated with a slight but significant elongation $(p<0.05)$ (Fig. 6).

\section{DISCUSSION}

INDO is a treatment widely used to induce closure of a patent DA in the preterm infant, but the reason for the frequently noted clinical failure of this therapy is not well understood. The results of our studies indicate that repeated treatment with INDO may have an unforeseen adverse effect on DA closure in the preterm infant if SMC migration and subsequent intimal cushion formation is impeded.

Previous work in our laboratory has demonstrated that DA endothelial cells and SMC are both sources of $\mathrm{PGE}_{2}$ and $\mathrm{PGI}_{2}$ synthesis under basal (relatively hyperoxic) room air conditions and under conditions of severe hyperoxia $\left(95 \% \mathrm{O}_{2}\right)(28)$. In general, PG production in DA SMC tends to be higher than in endothelial cells. This is in keeping with previous studies in the intact tissue, inasmuch as skinned, deendothelialized preparations of DA exhibit production of large amounts of PG and contract after INDO treatment (29). Basal PG production has been demonstrated in infants with patent DA as well (30) and has been related to responsiveness to INDO.

Although we could not maintain DA or Ao SMC cultures under hypoxic (fetal) conditions because they will not grow (31), it is unlikely that the effects related to DA SMC migration are the result of an increase in PG production caused by relative hyperoxia in room air. We have previously shown that DA and Ao endothelial cells and SMC produce similar levels of $\mathrm{PGE}_{2}$ and $\mathrm{PGI}_{2}$ in culture under room air conditions and $\mathrm{SMC}$ from

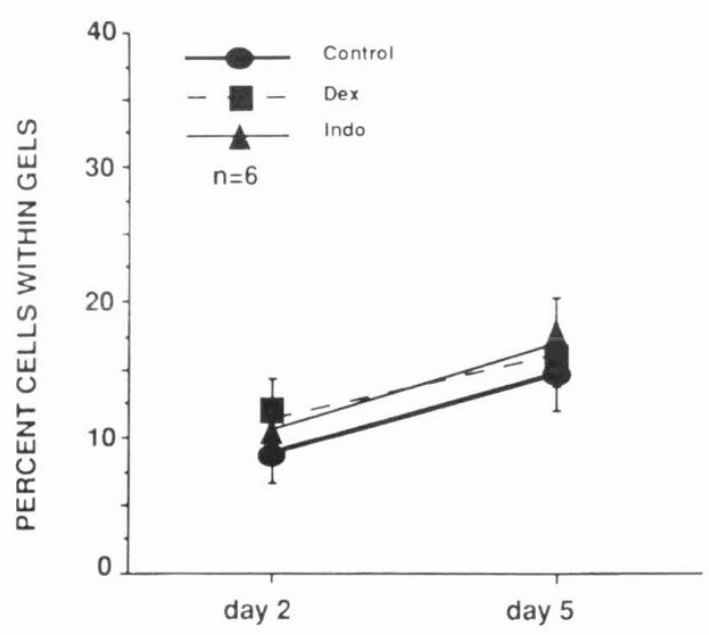

AORTA

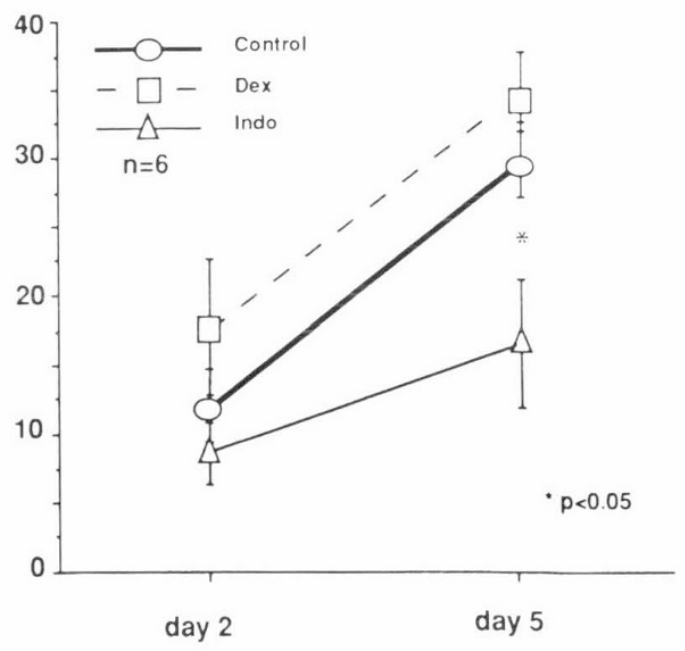

DUCTUS ARTERIOSUS

Fig. 1. Migration of Ao and DA SMC in three-dimensional collagen gels. Data are represented by means \pm SEM for $n=6$ in each group. Two $\mathrm{d}$ after seeding, no differences were observed in the migration of DA or Ao SMC under control or treatment conditions. At d 5, more DA compared with Ao SMC have migrated into the gels $(p<0.05)$. In INDO-treated DA SMC, migration was inhibited to the level seen in the Ao $(*, p<0.05)$. DEX treatment of DA SMC resulted in an insignificant increase in migration. 
Aorta
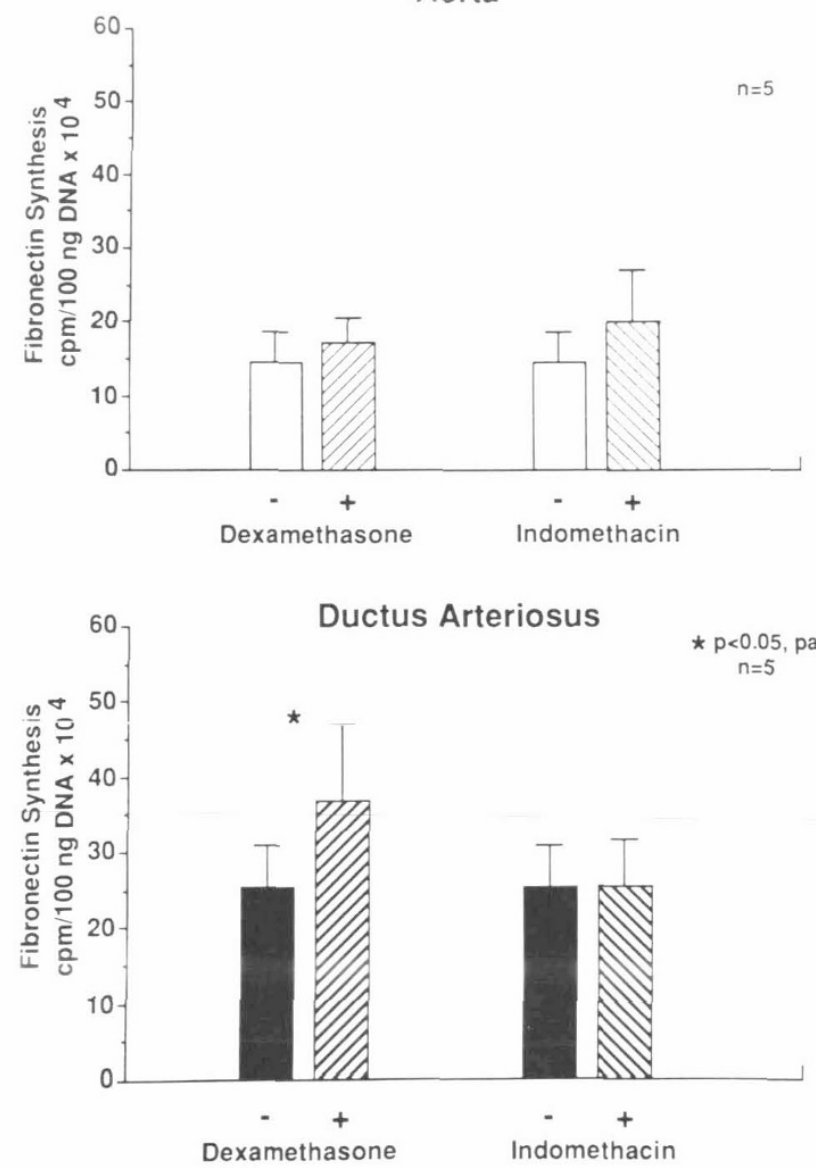

Fig. 2. FN production by Ao and DA SMC. Control DA SMC produced nearly twice as much FN as did Ao SMC $(p<0.05)$. INDOtreated DA SMC continued to produce basal levels of FN, whereas DEX treatment resulted in a $44 \%$ increase in FN synthesis by DA SMC $\left(^{*}, p\right.$ $<0.05$ ). Neither drug significantly influenced Ao SMC FN production.

both vascular sites respond to severe hyperoxia $\left(95 \% \mathrm{O}_{2}\right)$ with similar increases in PG production (28).

Normally, INDO, by decreasing endothelial cell and SMC PG production, effects a muscular contraction of the DA resulting in the apposition of the intimal cushions leading to luminal obliteration. When INDO is administered to a preterm infant at a time point before the complete formation of intimal cushions, the muscular contraction might fail to achieve luminal obliteration. Moreover, we speculate, based upon our results, that INDO therapy at this time point may, through its influence on the cytoskeleton of DA SMC, retard the further development of the intimal cushions.

We chose a dose of INDO that we have shown in our previous studies completely inhibits production of PG in SMC (unpublished observations). It is possible that the effect observed was associated with some cAMP- or non-cAMP-mediated PG function unrelated to alterations in the cytoskeleton. It would therefore be of interest in future studies to replace $\mathrm{PGE}_{2}$ or $\mathrm{PGI}_{2}$ or to stimulate CAMP in INDO-treated DA SMC and to determine whether this alters the cytoskeleton, produces an elongated cell shape, and increases SMC migration.

The properties and behavior of cells are modified by changes in the production of extracellular matrix components with which they are in contact (32). Enhanced DA SMC migration has been shown to be related to increased FN production by DA compared with Ao SMC (6), and this is associated with an elongated shape of DA relative to Ao SMC consistent with a motile phenotype. It is believed that SMC migration in gels is dependent upon the production of a FN gradient that results from increased secretion

\section{Aorta}

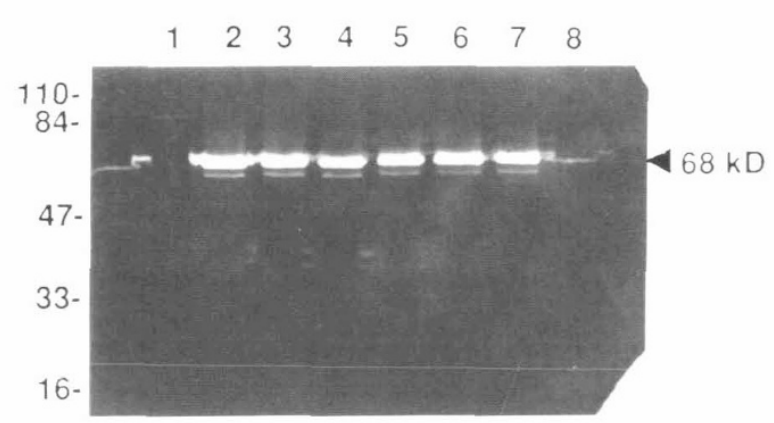

Ductus Arteriosus

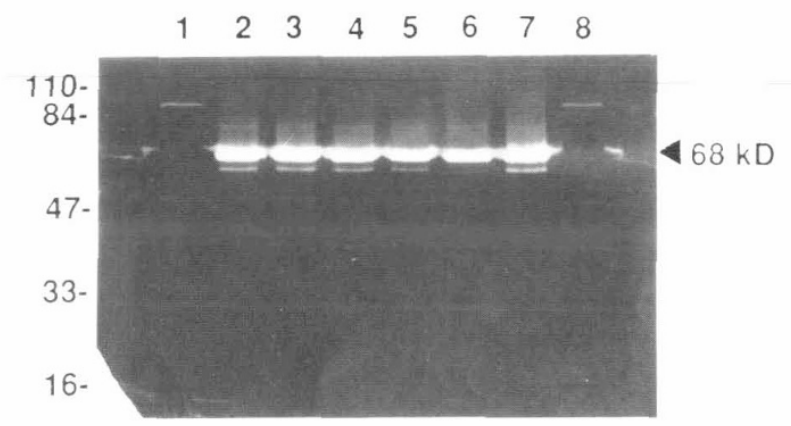

Fig. 3. Representative zymograms demonstrating type I collagenase activity by Ao (top) and DA (bottom) SMC. Lanes $I$ and 8 represent molecular mass standards that are not well visualized on this photograph but that could be identified on the stained gel and that are indicated on the left-hand side. A $68-\mathrm{kD}$ type I collagenase was present in similar amounts in control, DEX-, and INDO-treated Ao or DA SMC, lanes 24 , respectively. Lanes 5-7 represent duplicates.

of this matrix component (33). When FN antibodies or RGD peptides were added to collagen gels, we showed that DA SMC adopted a stellate appearance resembling the appearance of Ao SMC and no longer exhibited increased migration (7). DEX, despite effecting a $44 \%$ increase in $\mathrm{FN}$ production by the DA cells, was not able to enhance the migration of those cells, although a trend toward enhanced migration was apparent. It is possible that a larger sample size or determining cell migration at a later time point or a higher dose of DEX may have shown a significant difference in migration. Alternatively, the DA SMC may already possess a maximally "migratory phenotype" and therefore are not influenced by the presence of greater amounts of FN. The regulation of FN is different in the DA and Ao in that there appears to be an enhanced efficiency of translation of FN mRNA in the DA in comparison to the Ao, where there seems to be a "translational block" (34). Therefore, even if corticosteroids were increasing FN mRNA half-life in the Ao, it is possible that the reduced mRNA translation efficiency in the Ao would result in no net increase in protein production, and this might explain the lack of DEX effect on Ao SMC FN production. The inhibition by INDO of DA SMC migration was not associated with a decrease in FN production by these cells, nor did INDO influence the production of the collagenases that are associated with cell migration.

Many extracellular matrix receptors have been identified and shown to contain cytoskeleton-linked transmembrane domains (35). FN receptors are linked to the actin cytoskeleton of SMC 

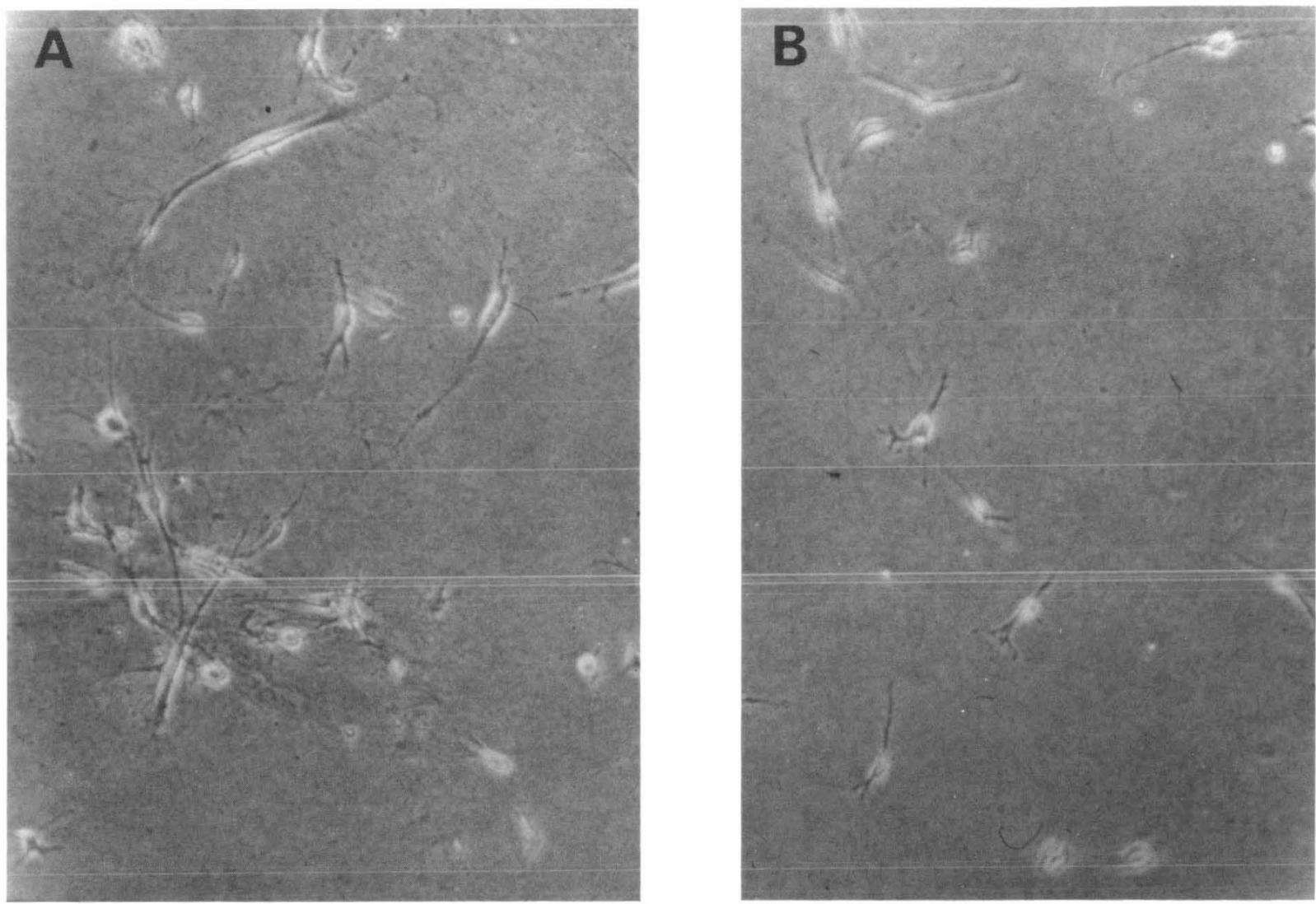

Fig. 4. Phase contrast photomicrographs of representative control DA SMC $(A)$ demonstrating characteristic elongated spindle morphology. INDO-treated cells demonstrate shortened stellate appearance $(B)$. Magnification $\times 150$.

(36). PG, by increasing intracellular cAMP levels, can regulate both FN production and F-actin polymerization (10). Moreover, an increase in expression of $\mathrm{FN}$, the $\mathrm{FN}$ receptor, and actin observed in cells undergoing serum stimulation reflects the need for newly formed cells to anchor and undergo the necessary morphologic changes related to adhesion and spreading on the matrix (10). What appears most likely is that PG prevent closure of the fetal DA due to sudden hemodynamic changes or fluctuations in oxygen saturation while at the same time, in association with enhanced FN synthesis, they maintain F-actin polymerization and DA SMC morphology compatible with efficient migration for the purpose of forming intimal cushions. Removal of this matrix-cytoskeleton interaction by inhibiting prostacyclin synthase with INDO may result in the acquisition by DA SMC of the Ao SMC phenotype that is contractile as opposed to synthetic or motile and therefore unsuited to migration. Comparison of cell morphology and length between the control and INDO-treated DA SMC in relation to the observed differences in migration in three-dimensional collagen gels suggest that INDO constricts the DA by effecting the contraction of individual DA SMC. These contracted DA SMC then have a phenotype similar to Ao SMC that is unsuited to efficient migration, inhibiting further intimal cushion development and thus possibly leading to INDO treatment failure and persistent DA patency.

The apparent lengthening of Ao SMC during DEX therapy seems to be unrelated to increased FN synthesis by these cells. Clyman et al. (37) have demonstrated that DA SMC migration is dependent on expression of laminin receptors. In studies evaluating the relationship of laminin to gut epithelial cell development, DEX was found to have no effect on laminin production by those cells but did induce a shift from secreted to cell-associated laminin molecules, suggesting an influence on receptor number or availability (38). The observed elongation of DEX-treated Ao SMC may have been associated with increased adhesion to laminin, whereas DA SMC, already having a maxi- mally migratory phenotype, are not further influenced by DEXenhanced laminin adhesion. Alternatively, DEX may have a stabilizing effect on Ao SMC F-actin cytoskeleton, as has been demonstrated in other cell types (39), allowing the Ao SMC to lengthen. The fetal DA SMC may already exist at its maximum length necessary for efficient migration. DEX did not induce a sufficient increase in Ao SMC length to match that of DA SMC, and this may have accounted for the lack of increased motility.

Any pharmacologic manipulation of the developing DA for the purpose of its constriction may similarly retard intimal cushion formation. Therefore, future research should be directed toward methods of enhancing intimal cushion formation before DA constrictive therapy. Clinical data from trials of antenatal maternal steroid administration demonstrate a reduction in the incidence of patent DA in the babies born prematurely to these mothers (40). Whether this effect is related to decreased severity of respiratory distress syndrome in these babies or an actual effect on human fetal DA FN production and intimal cushion formation is not known at this time.

The finding of an alteration in cell phenotype associated with decreased DA SMC migration as a result of treatment with the nonsteroidal antiinflammatory agent INDO provides insight into a possible mechanism of INDO treatment failure, inasmuch as DA SMC migration is necessary to complete intimal cushion formation. Improved understanding of the regulation of the structural development of the DA may lead to more specific means of postnatally manipulating the patency or closure of the DA.

Acknowledgments. The authors thank Joan Jowlabar and Susy Taylor for their secretarial assistance in preparing this manuscript, Dr. T. Cruz and J. Zamora of Mount Sinai Hospital for their assistance in preparation of the collagenase assays, and David Ettenson for his help with the F-actin staining. 

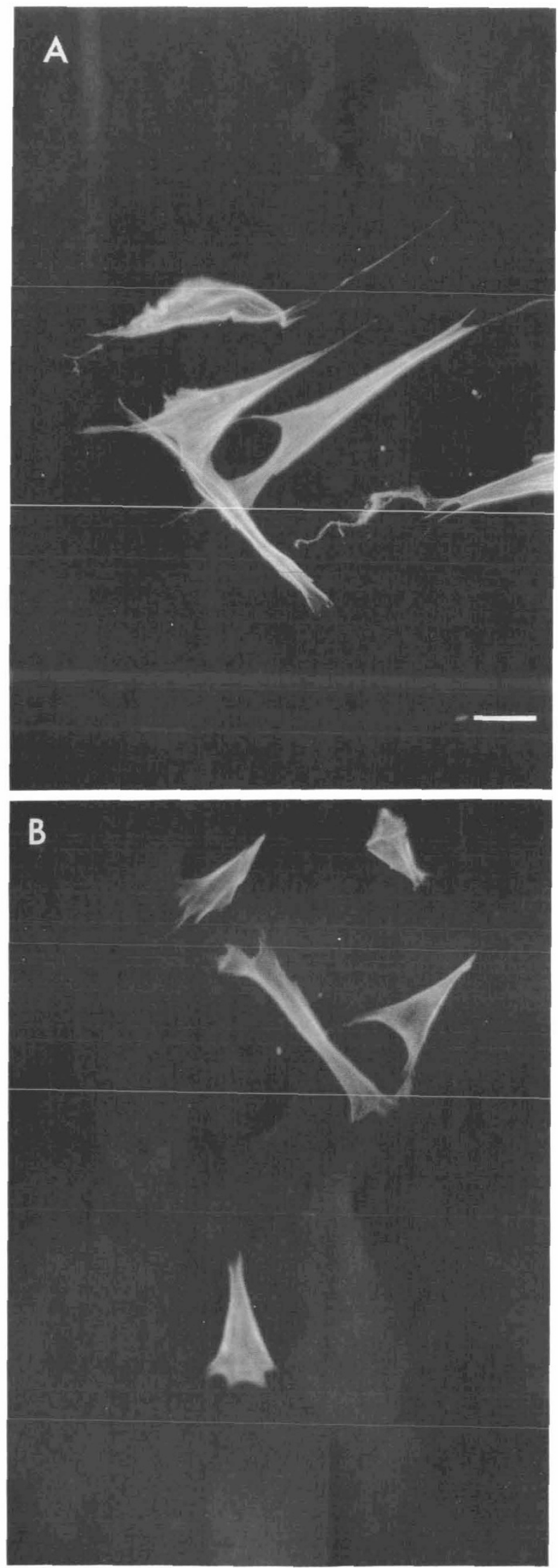

Fig. 5. Phototomicrographs of representative DA SMC stained with rhodamine-phalloidin for F-actin. The elongated spindle morphology of DA SMC $(A)$ and shortening of cells after INDO treatment $(B)$ are observed. Scale bar $=20 \mu \mathrm{m}$. Magnification $\times 500$.
Aorta

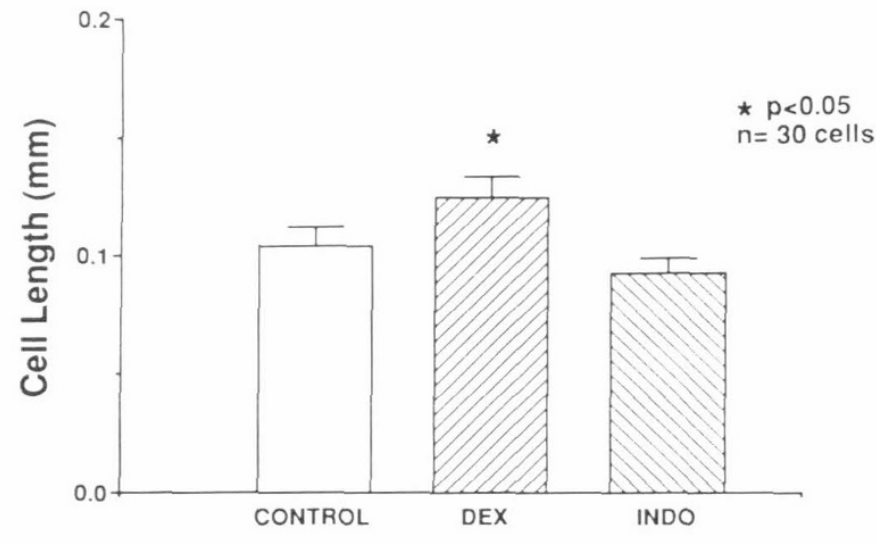

Ductus Arteriosus

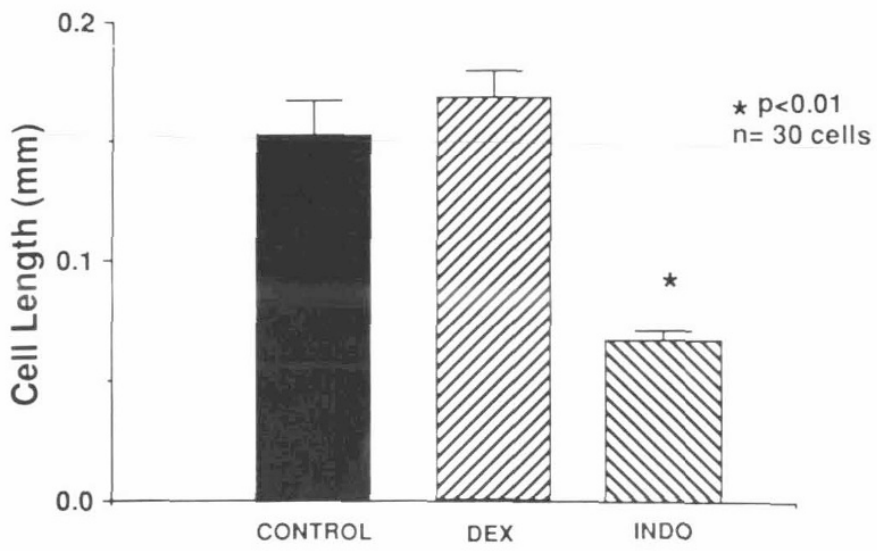

Fig. 6. Cell length of Ao and DA SMC as determined by semiautomatic interactive image analysis. Values are represented by mean \pm SEM for 30 cells. Ao SMC length was not significantly reduced by INDO treatment, whereas DEX treatment resulted in a slight elongation of Ao SMC $\left(^{*}, p<0.05\right)$. INDO-treated DA SMC were significantly shorter than DA controls $(*, p<0.01)$.

\section{REFERENCES}

1. Coceani F. Breen CA. Lees J, Falck J. Olley P 1988 Further evidence implicating a cytochrome P-450-mediated reaction in the contractile tension of the lamb ductus arteriosus. Circ Res 62:471-477

2. Coceani F. Armstrong C, Kelsey L 1989 Endothelin is a potent constrictor of the lamb ductus arteriosus. Can J Physiol Pharmacol 67:902-904

3. Coceani F. Kelsey L 1991 Endothelin-1 release from lamb ductus arteriosus: relevance to postnatal closure of the vessel. Can J Physiol Pharmacol 69:218221

4. Gittenberger-de Groot AC. Strengers JLM. Mettnick M. Poelman RE. Harink F 1985 Histologic studies on normal and persistent ductus arteriosus in the dog. J Am Coll Cardiol 6:394-404

5. DeReeder EG, Girard N, Poelmann RE, van Munsteren JC. Patterson DF. Gittenberger-de Groot AC 1988 Hyaluronic acid accumulation and endothelial cell detachment in intimal thickening of the vessel wall. Am J Pathol 132:574-585

6. Boudreau N, Rabinovitch M 1991 Developmentally regulated changes in extracellular matrix in endothelial and smooth muscle cells in the ductus arteriosus may be related to intimal proliferation. Lab Invest 64:187-199

7. Boudreau N. Turley E. Rabinovitch M 1991 Fibronectin, hyaluronan, and a hyaluronan binding protein contribute to increased ductus arteriosus smooth muscle cell migration. Dev Biol 143:235-247

8. deReeder EG, Gittenberger-de Groot AC, van Munsteren JC, Poelman RE. Patterson DF. Keirse JNC 1989 Distribution of prostacyclin synthase, 6keto-prostaglandin $F_{1 a}$, and 15-hydroxy-prostaglandin dehydrogenase in the normal and persistent ductus arteriosus of the dog. Am J Pathol 135:881887

9. Rubin R. Hoek JB 1990 Inhibition of ethanol-induced platelet activation by agents that elevate cAMP. Thromb Res 58:625-632

10. Dean DC, McQuillan JJ, Weintraub S 1990 Serum stimulation of fibronectin gene expression appears to result from rapid serum-induced binding of nuclear proteins to a cAMP response element. J Biol Chem 265:3522-3527 
11. Dean DC, Newby RF, Bourgeois S 1988 Regulation of fibronectin biosynthesis by dexamethasone, transforming growth factor- $\beta$ and cAMP in human cell lines. J Cell Biol 106:2159-2170

12. Liotta LA, Rao CN, Wewer M 1986 Biochemical interactions of tumor cells with the basement membrane. Annu Rev Biochem 55:1037-1058

13. Librach CL, Werb Z, Fitzgerald ML. Chiu K. Corwin NM. Esteves RA Grobelny D, Galardy R, Damsky CH, Fisher SJ 1991 92-kD Type IV collagenase mediates invasion of human cytotrophoblasts. J Cell Biol 113:437-449

14. Rajabi M, Solomon S, Poole R 1991 Hormonal regulation of interstitial collagenase in the uterine cervix of the pregnant guinea pig. Endocrinology 128:863-871

15. Blackburn Jr WD, Loose LD, Heck LW, Chatham WW 1991 Tenidap, in contrast to several available nonsteroidal anti-infammatory drugs, potently inhibits the release of activated neutrophil collagenase. Arthritis Rheum $34: 211-216$

16. Joyce NC 1990 In vitro pharmacologic separation of corneal endothelial migration and spreading responses. Invest Ophthalmol Vis Sci 31:18161826

17. Downey GP, Elson EL, Schwab III B, Erzurum SC, Young SK, Worthen GS 1991 Biophysical properties and microfilament assembly in neutrophils: modulation by cyclic AMP. J Cell Biol 114:1179-1190

18. Coceani F, White E, Bodach E, Olley PM 1979 Age-dependent changes in the response of the lamb ductus arteriosus to oxygen and ibuprofen. Can J Physiol Pharmacol 57:825-83!

19. Rabinovitch M, Beharry S, Bothwell T, Jackowski G 1988 Qualitative and quantitative differences in protein synthesis comparing fetal lamb ductus arteriosus endothelium and smooth muscle with cells from adjacent vascular sites. Dev Biol 130:250-258

20. Ross R 1971 The smooth muscle cell II: growth of smooth muscle in culture and formation of elastic fibers. J Cell Biol 50:172-186

21. Wren FE, Schor AM, Schor SL, Grant ME 1986 Modulation of smooth muscle cell behavior by platelet-derived factors and the extracellular matrix. J Cell Physiol 127:297-302

22. Honn KV, Grossi IM, Fitzgerald LA, Umbarger LA, Diglio CA, Taylor JD 1988 Lipoxygenase products regulate IRGpIIb/IIIa receptor mediated adhesion of tumor cells to endothelial cells, subendothelial matrix and fibronectin. Proc Soc Exp Biol Med 189:130-135

23. Furcht LT, Mosher DF, Wendelschafer-Crabb G, Foidart JM 1979 Reversal by glucocorticoid hormones of the loss of a fibronectin and procollagen matrix around transformed human cells. Cancer Res 39:2077-2083

24. Wrana JL, Maeno M, Hawrylshyn B, Yao K-L, Domenicucci C, Sodek J 1988 Differential effects of transforming growth factor $\beta$ on the synthesis of extracellular matrix proteins by normal fetal rat calvarial bone cell population. J Cell Biol 106:915-924
25. Laemmli UK 1970 Cleavage of structural proteins during the assembly of the head of bacteriophage $\mathrm{T}_{4}$. Nature 227:680-685

26. West DC, Sattar A, Kumar S 1985 A simplified in situ solubilization procedure for the determination of DNA and cell number in tissue cultured mammalial cells. Anal Biochem 147:289-295

27. Unemori EN, Werb Z 1986 Reorganization of polymerized actin: a possible trigger for induction of procollagenase in fibroblasts cultured in and on collagen gels. J Cell Biol 103:1021-1031

28. Rabinovitch M, Boudreau N, Vella G, Coceani F, Olley PM 1989 Oxygenrelated prostaglandin synthesis in ductus arteriosus and other vascular cells. Pediatr Res 26:330-335

29. Coceani F, Huhtanen D, Hamilton NC, Bishai I, Olley PM 1986 Involvement of intramural prostaglandin $E_{2}$ in prenatal patency of the lamb ductus arteriosus. Can J Physiol Pharmacol 64:737-744

30. Hammerman C, Zaia W, Berger S, Strates E 1986 Prostaglandin levels: predictors of indomethacin responsiveness. Pediatr Cardiol 7:61-65

31. Benitz WE, Coulson JD, Lesser DS, Bernfield M 1986 Hypoxia inhibits proliferation of fetal pulmonary arterial smooth muscle cells in vitro. Pediatr Res 20:966-972

32. Bissel MJ, Hall HG, Parry G 1982 How does the extracellular matrix direct gene expression? J Theor Biol 99:31-69

33. Thierry JP, DuBand JL, Dufour S, Savanger P. Imhof BA 1989 Roles of fibronectin in embryogenesis. In: Mosher F (ed) Fibronectin Biology of the Extracellular Matrix. Academic Press, New York, pp 181-212

34. Boudreau N, Clausell N, Boyle J, Rabinovitch M 1992 Transforming growth factor- $\beta$ regulates increased ductus arteriosus endothelial glycosaminoglycan synthesis and a post-transcriptional mechanism controls increased smooth muscle cell fibronectin, features associated with intimal proliferation. Lab Invest 67:350-359

35. MacDonald JA 1989 Matrix regulation of cell shape and gene expression. Curr Opin Cell Biol 1:995-999

36. Burn P, Kupfer A, Singer SJ 1988 Dynamic membrane-cytoskeletal interactions: specific association of integrin and talin arises in vivo after phorbol ester treatment of peripheral blood lymphocytes. Proc Natl Acad Sci USA $85: 497-501$

37. Clyman RI, Kramer RH, Mauray F 1992 Ductus arteriosus migration on collagen: dependence on fibronectin, laminin and integrin receptors. Pediatr Res 31:1175A(abstr)

38. Simo P, Simon-Assman P, Arnold C, Kedinger M 1992 Mesenchyme mediated effects of dexamethasone on laminin in cocultures of embryonic gut epithelial cells and mesenchyme derived cells. J Cell Sci 101:161-171

39. Castellino F, Heuser J, Marchetti S, Bruno B, Luini A 1992 Glucocorticoid stabilization of actin filaments: a possible mechanism for inhibition of corticotropin release. Proc Natl Acad Sci USA 89:3775-3779

40. Clyman RI, Ballard PL, Sniderman S, Ballard RA, Roth R, Heymann MA, Granberg JP 1981 Prenatal administration of betamethasone for prevention of patent ductus arteriosus. J Pediatr 98:123-126 